\title{
Mid-term and late results of endovascular treatment for symptomatic carotid artery stenosis under proximal protection
}

\author{
Paweł Latacz ${ }^{1}$, Marian Simka², Marcin Krzanowski ${ }^{3}$, Katarzyna Krzanowska ${ }^{3}$, Paweł Brzegowy4, Bartłomiej Łasocha ${ }^{4}$, \\ Tadeusz J. Popiela ${ }^{4}$ \\ ${ }^{1}$ Department of Neurology, Jagiellonian University Medical College, Krakow, Poland \\ ${ }^{2}$ Department of Anatomy, University of Opole, Opole, Poland \\ ${ }^{3}$ Department of Nephrology, Jagiellonian University Medical College, Krakow, Poland \\ ${ }^{4}$ Chair of Radiology, Jagiellonian University Medical College, Krakow, Poland
}

Videosurgery Miniinv 2021; 16 (1): 175-182

DOI: https://doi.org/10.5114/wiitm.2020.94519

\begin{abstract}
Introduction: Although filters are still preferred during carotid stenting, proximal protection systems (PPS) are increasingly used during these procedures. PPS seem to be safer than distal systems, especially in symptomatic patients, but evidence supporting their use is limited.

Aim: This was a post hoc survey with 30-day mid-term and long-term follow up, which was aimed at assessment of the safety and efficacy of stenting of the internal carotid artery under PPS in symptomatic patients.

Material and methods: We analysed the results of stenting in 120 symptomatic patients presenting with at least $60 \%$ stenosis. Patients were aged $67.9 \pm 9.8$ years, and 12 patients were older than 80 years. An occlusion of contralateral artery was found in 5 patients and bilateral stenosis in 26 patients. The primary endpoint of this study was the proportion of patients who had new neurological events, including transient ischemic attack and minor or major stroke in 30-day follow-up. The secondary endpoint was a composite of technical and clinical success. During longterm follow-up we assessed new neurological events and stenoses of implanted stents.

Results: The incidence of new neurological events during 30-day follow-up was $0.8 \%$. The rate of technical success defined by secondary endpoint was 100\%. Mean internal carotid artery stenosis before and after stent implantation was $93.8 \pm 9 \%$ and $8.4 \pm 6.3 \%$, respectively $(p<0.001)$. Procedural success was achieved in all cases. During longterm follow-up there were two (1.7\%) asymptomatic in-stent stenoses and no (0\%) new neurological events.

Conclusions: Endovascular management of symptomatic carotid stenosis under PPS is safe, feasible, and appears to be a good alternative to surgical endarterectomy.
\end{abstract}

Key words: stroke, stenting, carotid stenosis, proximal protection.

\section{Introduction}

Surgical endarterectomy and endovascular angioplasty represent established treatment modalities for stenosis of the internal carotid artery, which is responsible for about $20 \%$ of cerebral strokes. Nowadays surgical repair is still regarded as the method of choice, while angioplasty and stenting is an alternative treatment modality [1-6]. The main problem associated with transcutaneous angioplasty is cerebral microembolism during endovascular manoeuvres. Although distal protection with filters is primarily used for the protection of cerebral circulation, a proximal protection system, such as the Mo.Ma,

\section{Address for correspondence}

Paweł Latacz MD, PhD, Department of Neurology, Jagiellonian University Medical College, University Hospital, 2 Jakubowskiego St,

30-688 Krakow, Poland, phone: +48 1240025 51, e-mail: pawlat@me.com 
is increasingly used. These systems are characterised by a higher safety profile in comparison with distal protection devices $[7,8]$. A proximal protection system seems to be particularly advantageous in symptomatic patients and those older than 80 years. Research has demonstrated that there are fewer microembolic complications after procedures performed under proximal protection in comparison with carotid stenting with the use of distal protection devices. In this retrospective study we analysed early, mid-, and long-term results of carotid angioplasty with stenting under proximal protection in symptomatic patients.

\section{Aim}

This post hoc survey, with 30-day mid-term and up to 4.5-year long-term follow-up, was aimed at assessment of safety and efficacy of stenting procedure with the use of proximal protection for the treatment of internal carotid artery (ICA) stenosis in symptomatic patients presenting with at least $60 \%$ stenosis of this artery. The primary endpoint of this study was the proportion of patients who, within 30 days of carotid intervention, had a new neurologi-

Table I. Inclusion and exclusion criteria

Inclusion criteria:

- Symptomatic patient with internal carotid artery stenosis $\geq 60 \%$ as defined by duplex ultrasound, angiography or MR angiography

- Symptomatic lesions of internal carotid artery is defined as a stenosis associated with ipsilateral TIA, amaurosis fugax, ischaemic stroke or retinal infarction

- Unstable symptomatic lesions of carotid artery, a presence (or suspect) of thrombi inside the lesion, and tortuousness of the target artery

Exclusion criteria:

- Rarget lesion that has been previously stented

- Highly calcified lesions

- Occlusion of the contralateral carotid artery without adequate collateral circulation through the circle of Willis (revealed by means of the transcranial Doppler sonography)

- An acute ipsilateral stroke

- Other severe pathologies of the brain resulting is significant loss of cerebral tissue and/or significant neurological deficits

- History of haemorrhagic transformation of ischemic stroke

- Severe co-morbidities (such as cancer or decompensated heart failure)

- Allergy to aspirin or clopidogrel; to iodinated contrast media

- A lack of adequate vascular access cal event, including transient ischemic attack (TIA) or minor or major stroke. The secondary endpoint was the mid-term and late composite of technical and clinical success. This success was evaluated $24-48 \mathrm{~h}$ after the procedure, and then at 30-day mid-term and late follow-ups, and was defined as a technically successful carotid stenting, which was not followed by death, stroke, or other cardiovascular event, or by a stent occlusion/restenosis.

\section{Material and methods}

We analysed results of the treatment of 120 consecutive patients (44 women and 76 men) who were managed by our team from March 2014 to June 2018. The mean age of enrolled patients was 67.9 \pm 9.8 years, and $12(10 \%)$ patients were aged more than 80 years. All patients presented with at least $60 \%$ stenosis of the ICA, demonstrated by means of colour-coded duplex sonography, computed tomography (CT) angiography, or magnetic resonance (MR) angiography. Standard preprocedural management of the patients comprised multidisciplinary assessment, including neurological, vascular, and cardiologic consultations. Potential risks and benefits associated with the planned procedure were discussed with patients, and all of them gave their written, informed consent. The inclusion and exclusion criteria are presented in Table I.

All patients analysed in this study were symptomatic, which meant that they had an ipsilateral neurological ischaemic event during the 60 days before the endovascular procedure. An ischaemic lesion was considered ipsilateral if it occurred in the cerebral tissue supplied by the target carotid artery. Patients were managed at least two days after a neurological event, preferentially on the $7^{\text {th }}-14^{\text {th }}$ day, depending on the findings of CT or MRI of the brain and the appearance of cerebral lesions revealed by this test. In this patient cohort the mean time from neurological event to the intervention was 18.7 days.

In addition to the demographic and clinical data, we also analysed angiographic characteristics, such as the presence of coexisting lesions in other arteries supplying the brain, including intracranial stenoses. Also, we assessed the endovascular technique used (type of protection, type of stent, duration of the procedure, and duration of the occlusion of the artery). Patients' characteristics and localisation of vascular lesions are given in Table II. 
Endovascular procedures were performed by a well-trained interventionalist, with an expertise of over 1000 endovascular procedures already carried out. All procedures were done under local anaesthe-

Table II. Demographic and clinical characteristics of the patients (number of patients: $N=120$; number of procedures: $N=120$ )

\begin{tabular}{|c|c|c|}
\hline Patients' characteristics & $N$ & Percent \\
\hline Patients' age, mean \pm SD [years] & \multicolumn{2}{|c|}{$67.9 \pm 9.8$} \\
\hline Patients older than 80 year & 12 & 10 \\
\hline Male/female ratio & \multicolumn{2}{|c|}{$76 / 44$} \\
\hline \multicolumn{3}{|l|}{ Risk factors: } \\
\hline Stable coronary heart disease & 25 & 20.8 \\
\hline Arterial hypertension & 108 & 90.0 \\
\hline Diabetes mellitus type 2 & 34 & 28.3 \\
\hline Dislipidemia & 80 & 66.7 \\
\hline Cigarette smoking & 29 & 24.2 \\
\hline Renal impairment & 5 & 4.2 \\
\hline Peripheral artery disease & 4 & 3.3 \\
\hline $\begin{array}{l}\text { Chronic obstructive pulmonary } \\
\text { disease }\end{array}$ & 5 & 4.2 \\
\hline $\begin{array}{l}\text { History of percutaneous coronary } \\
\text { angioplasty }\end{array}$ & 13 & 10.8 \\
\hline History of myocardial infarction & 16 & 13.3 \\
\hline $\begin{array}{l}\text { History of transient ischemic } \\
\text { attack }\end{array}$ & 12 & 10.0 \\
\hline History of stroke & 108 & 90.0 \\
\hline $\begin{array}{l}\text { Bilateral stenosis of the internal } \\
\text { carotid artery }\end{array}$ & 26 & 21.7 \\
\hline $\begin{array}{l}\text { Occlusion of the internal carotid } \\
\text { artery }\end{array}$ & 5 & 4.2 \\
\hline Stenosis of the vertebral artery & 9 & 7.5 \\
\hline $\begin{array}{l}\text { Lesion in the left/right internal } \\
\text { carotid artery }\end{array}$ & $59 / 61$ & $49.2 / 50.8$ \\
\hline II/III type of the aortic arch & 23 & 19.2 \\
\hline Degree of stenosis, mean \pm SD & & \pm 14.2 \\
\hline $\begin{array}{l}\text { Time from neurological event to } \\
\text { the intervention, mean } \pm \text { SD [days] }\end{array}$ & & \pm 10.2 \\
\hline \multicolumn{3}{|l|}{$\begin{array}{l}\text { Localization of stenosis in the } \\
\text { internal carotid artery: }\end{array}$} \\
\hline C1-C2 segment & 109 & 90.8 \\
\hline C3-C4 segment & 11 & 9.2 \\
\hline
\end{tabular}

sia at the vascular access site. Catheter angiography, which was performed before and after angioplasty, evaluated both ipsi- and contralateral cerebral circulation. Except for 4 patients, who were protected with the Gore Flow Reversal System (Gore \& Associates, Inc., Flagstaff, AZ, USA); in all remaining patients the Mo.Ma (Medtronic, Minneapolis, MN, USA) system was used. Stent implantations were performed using the technique and armamentarium, which were tailored to the type and anatomy of the lesion. The time of the occlusion of carotid flow by protection systems ranged from 2.5 to 15 min (mean: $6.6 \pm 2.5$ min). Predilatation was performed in 24 out of 120 stenoses (20\%). In 6 patients two stents and in 1 patient three stents were implanted, primarily because of a massive protrusion of the plaques through the cells of stents. In 91 (75.8\%) patients we used close-cell stents, including dual-layered stents in 29 (24.1\%) patients. Details regarding protection devices and the stents utilised in this study, and the presence of embolic material secured by the protection systems, are given in Table III.

Table III. Characteristics of protection systems and stents utilized in 120 procedures in symptomatic patients (120 procedures)

\begin{tabular}{|c|c|c|}
\hline Variable & $\begin{array}{l}\text { Number } \\
\text { of cases }\end{array}$ & Percent \\
\hline \multicolumn{3}{|l|}{ Protection systems: } \\
\hline $\begin{array}{l}\text { Mo.Ma (Medtronic, Minneapolis, } \\
\text { MN, USA) }\end{array}$ & 116 & 96.6 \\
\hline $\begin{array}{l}\text { Gore Flow Reversal System (Gore \& } \\
\text { Associates, Inc., Flagstaff, AZ, USA) }\end{array}$ & 4 & 3.4 \\
\hline $\begin{array}{l}\text { Time of occlusions system, } \\
\text { mean } \pm \text { SD [min] }\end{array}$ & \multicolumn{2}{|c|}{$6.6 \pm 2.5$} \\
\hline \multicolumn{3}{|l|}{ Stents: } \\
\hline Precise (Cordis, Fremont, CA, USA) & 29 & 24.2 \\
\hline $\begin{array}{l}\text { Carotid Wallstent (Boston Scientif- } \\
\text { ic, Natick, MA, USA) }\end{array}$ & 49 & 40.8 \\
\hline $\begin{array}{l}\text { Cristallo Ideale (Medtronic, Minne- } \\
\text { apolis, MN, USA) }\end{array}$ & 13 & 10.8 \\
\hline RoadSaver (Terumo, Tokyo, Japan) & 29 & 24.2 \\
\hline \multicolumn{3}{|l|}{$\begin{array}{l}\text { Macroscopically visible embolic ma- } \\
\text { terial in the protection system: }\end{array}$} \\
\hline Single plaque or thrombus & 31 & 25.8 \\
\hline A little of debris & 3 & 2.5 \\
\hline A lot of debris & 3 & 2.5 \\
\hline
\end{tabular}


All patients received aspirin $75 \mathrm{mg} /$ day and clopidogrel $75 \mathrm{mg} /$ day. These drugs were administered 2-3 days before the planned procedure and then for at least 30 days after the intervention (typically for 3-6 months). During the procedure patients were administered intravenously heparin 100 units $/ \mathrm{kg}$. Periprocedural bradycardias were managed with the administration of atropine. Neurological assessment was performed before the procedure and on the first or second postprocedural day. A sonographic follow-up of the target arteries was performed on the first or second postprocedural day, then after 1 and 3 months, and thereafter every 6 months. In the case of a neurological event, an additional sonographic and neurological assessment was performed.

Patients were advised to report any neurological events that occurred during follow-up. Neurological symptoms were categorised as follows: transient ischaemic attack, which was defined as an acute neurological deficit resulting from focal temporary cerebral or retinal ischaemia that lasted less than $24 \mathrm{~h}$; stroke, which was defined as a new cerebrovascular event of ischaemic or haemorrhagic aetiology resulting in cerebral infarction and neurological deficit. Strokes were further classified as: minor - with neurological deficits lasting less than 30 days or lasting longer than 30 days, but presenting with small deficit (up to 4 points in the National Institute of Health Stroke Scale); major - with neurological deficits lasting longer than 30 days; and fatal - a stroke (ischaemic or haemorrhagic) resulting in death.

\section{Statistical analysis}

Continuous variables were expressed as means \pm standard deviation (SD); categorical variables were expressed as percentages. Analysis of normality was performed with the Kolmogorov-Smirnov test. Comparison of categorical variables between the groups was performed using the $\chi^{2}$ test. Comparisons of continuous variables between the two groups were performed using the independent samples $t$-test. Multivariate stepwise backward conditional logistic regression analysis was used to determine independent predictors of risk of intervention. All significant parameters in the univariate analysis were selected in the multivariate model. The significance of the two-tailed $p$ was set at $p<0.05$. Statistical analysis was performed using the SPSS software (Statistical Package for the Social Sciences (version 25.0 for MacOS, SPSS Inc., Chicago, IL, USA).

\section{Results}

The degree of stenosis of the ICA ranged from $60 \%$ to $99 \%$ (mean \pm SD: $93.8 \pm 14.6 \%$ ), and the majority of patients presented with over $70 \%$ stenosis. An occlusion of contralateral internal carotid artery was found in $5(4.1 \%)$ patients and bilateral stenosis in $26(21.6 \%)$ patients. In all cases the endovascular procedure was successful. All patients completed the 30-day follow-up. There were neither fatalities nor major strokes following the intervention in this patient cohort. The mean stenosis of internal carotid artery before and after stent implantation was $93.8 \pm 14.2 \%$ and $8.4 \pm 6.3 \%$, respectively $(p<0.001)$.

An example of a symptomatic patient with bilateral, critical carotid stenosis qualified for angioplasty with the use of a proximal protection system is shown in Photo 1.

The incidence of new neurological events during the 30-day follow-up (the primary endpoint) was $0.8 \%$. This one ipsilateral minor stroke occurred on the fifth postprocedural day in a 62-year-old male, who underwent stenting (Carotid WALLSTENT stent) of the right ICA under protection with the use of the Mo.Ma device. Because the stent was patent, this event probably resulted from a cardiogenic embolism. The rate of technical success defined by the secondary endpoint was $100 \%$.

Five (4.1\%) patients developed neurological symptoms after introduction of the protection device, two of them presented with contralateral stenoses of the ICA, but there were no clinical consequences related to this intolerance of proximal protection. Periprocedurally 8 (6.6\%) patients developed hypotension, which was managed with intravenous administration of crystalloids, but it did not result in further clinical sequelae. In 2 such patients an additional administration of dopamine was needed. Apart from these rather minor events, there were no serious periprocedural complications. Logistic multivariate analysis revealed some risk factors significantly predisposing for the intolerance of a proximal protection device. These comprised patients' age (intolerance of the introduction of protection device was more often seen in patients older than 

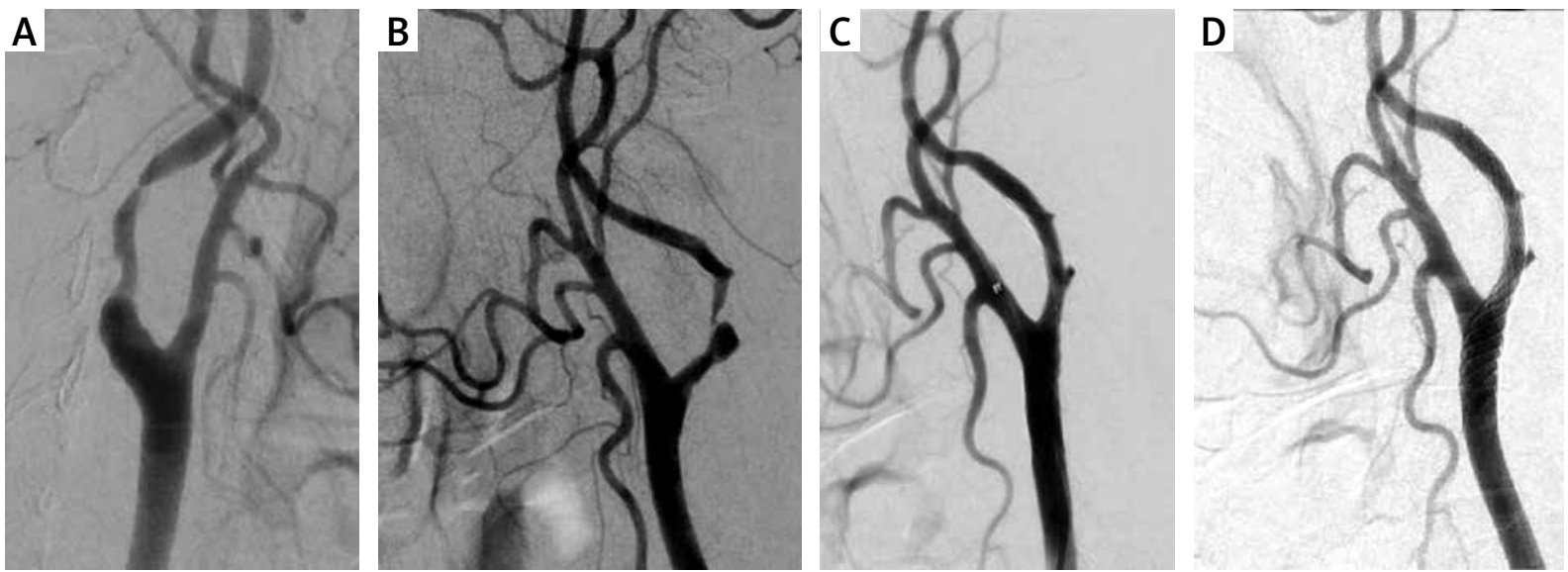

Photo 1. Patient with bilateral critical internal carotid artery stenosis. A - Critical, asymptomatic right internal carotid artery stenosis. B - Critical, symptomatic left internal carotid artery stenosis. C - Optimal angiographic result angioplasty with implantation of a RoadSaver stent in the left carotid internal artery with use of proximal protection Mo.Ma $8 \mathrm{~F}$ (visible balloon of Mo.Ma system in the external carotid artery). D - Final optimal angiographic angioplasty of left internal carotid artery - result after removal of the protection system, with good apposition of the stent in the common and internal left carotid arteries

80 years, $\mathrm{HR}=7.55 ; p=0.006)$, chronic obstructive pulmonary disease $(\mathrm{HR}=4.305 ; p=0.03)$, and cigarette smoking $(\mathrm{HR}=4.012 ; p=0.04)$.

The minimal duration of long-term follow-up was 5 months, and the mean duration was $594 \pm 369$ days. In 40 cases it was longer than three years; the maximal duration of the follow-up was 4.5 years.

There were no fatalities during the long-term follow-up. Except for the above-described stroke that occurred postprocedurally, there were no neurologic adverse events during follow-up. There was one non-fatal coronary event requiring percutaneous angioplasty. The overall probability of any incident-free survival was $95.8 \%$, and the probability of stroke-free survival was $99.2 \%$. Cumulative probability of restenosis-free survival in the implanted stent was $98.3 \%$, and such a survival regarding coronary events requiring angioplasty was $98.3 \%$ (Figure 1). Stents in 117 patients were patent and without significant stenoses. In 2 patients we found an asymptomatic in-stent restenosis. In both patients there were no neurological symptoms during 8-month follow-up after the re-intervention and the stents remained patent. It should be emphasised, however, that although the maximum observation period was over four years, the median duration of follow-up was about 2 years; thus, it is likely that during a longer follow-up the incidence rate of coronary and other non-neurological events will be higher.

\section{Discussion}

In our material carotid artery stenting with the use of proximal protection devices in symptomatic patients appeared to be a safe procedure.

Although carotid stenting is still preferentially performed with the use of distal protection, in symptomatic patients a high rate of ischaemic cerebral events after stenting with the use of filters, which is some studies was at the level of $10 \%$, cannot be ignored $[1-4,9]$. By contrast, such adverse events associated with stenting under proximal protection are less frequent. Open-label studies reported this risk at the level of $0.9-2.4 \%$ [10-13]. Similarly, there were fewer microembolic complications revealed by MRI after procedures performed under proximal protection in comparison with carotid stenting with the use of filters [14-16]. In our study, the Mo.Ma system was the preferred proximal protection device. This system has an established place in the armamentarium available for carotid interventions. In the non-randomised multicentre study ARMOUR, which evaluated a group of 222 patients and utilized the Mo.Ma system, the composite complication rate (comprising: stroke, death, and myocardial infarction) was $2.7 \%$, and the stroke rate during 30 days was $0.9 \%$ [12]. In another study the Mo.Ma system was used in 1300 patients. The composite complication rate (comprising stroke and death) at 30 -day follow-up was $1.4 \%$ (3\% in symptomatic 
A

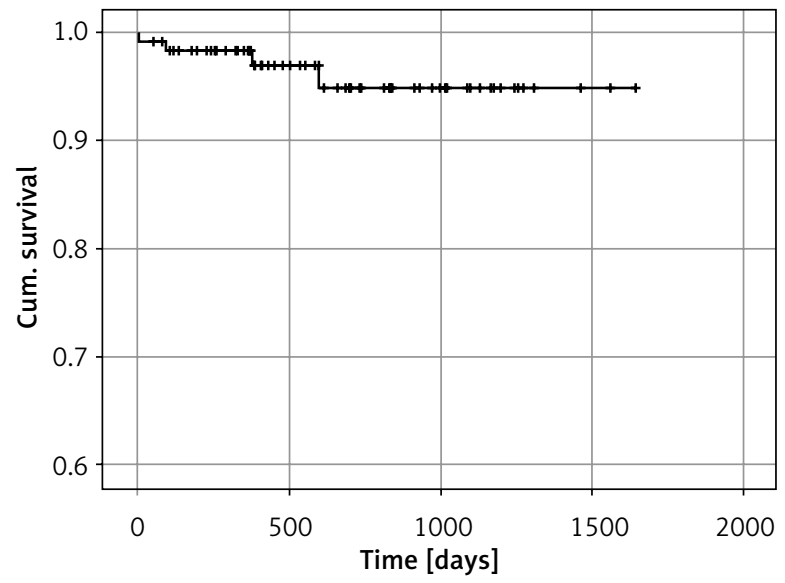

C

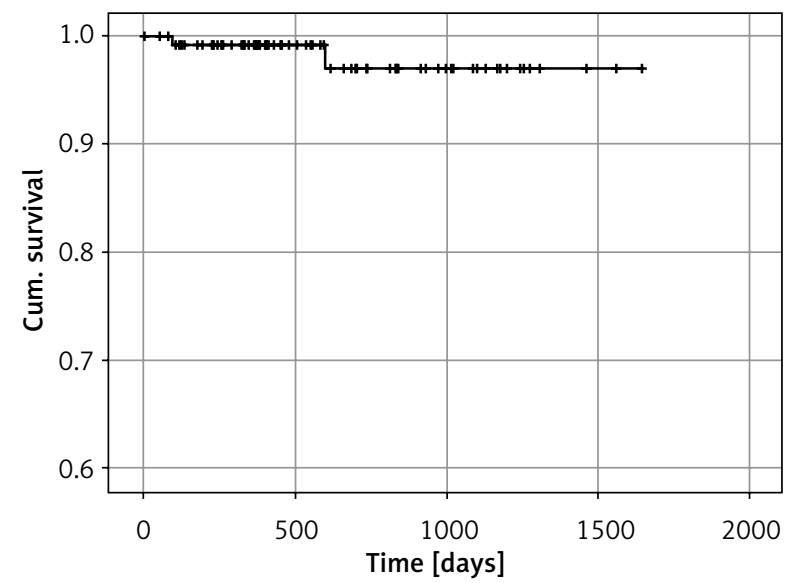

B

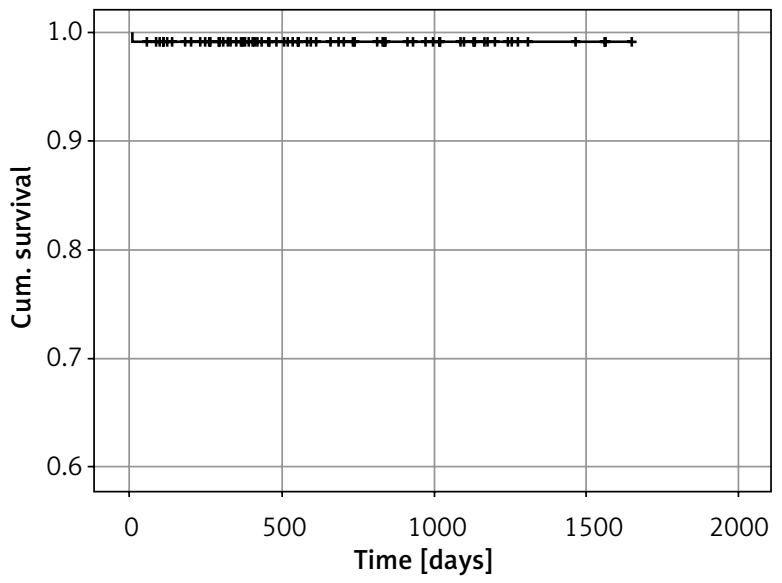

D

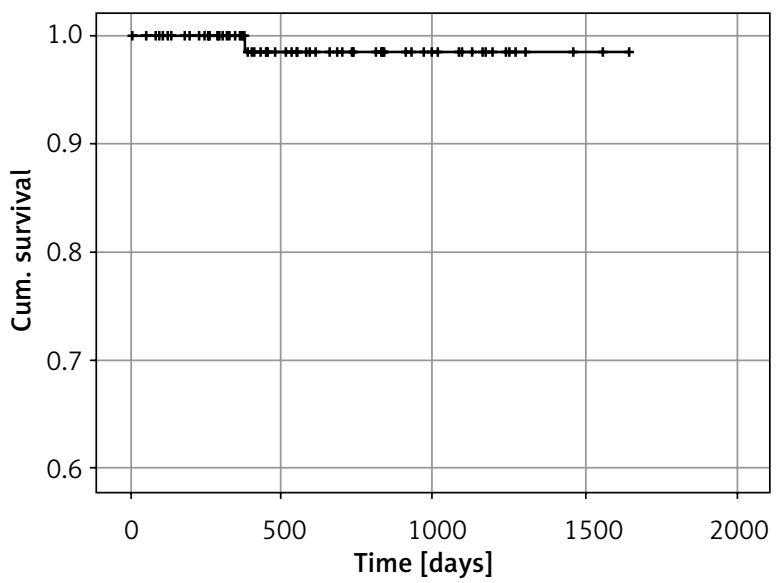

Figure 1. Kaplan-Meier event-free survival curves for symptomatic patients undergoing carotid artery stenting with proximal protection system. A - Overall survival free from any events. B - Cumulative survival freedom from stroke for all patients. C - Cumulative restenosis-free survival. D - Cumulative percutaneous coronary intervention-free survival

patients and $0.9 \%$ in asymptomatic ones). Of note, in this study a low operator experience (less than 100 procedures performed) was associated with a higher risk of adverse events [17]. Efficacy and safety of an alternative proximal protection system, the Gore Flow Reversal System, have been evaluated in the multicentre prospective, nonrandomised study EMPiRE [18]. This study involved 245 patients, of whom $30 \%$ were symptomatic and $16 \%$ were older than 80 years. Of note, in this study a contralateral stenosis or occlusion was not the exclusion criterion, and actually $10.5 \%$ of patients presented with such an occlusion. In this study the composite complication rate (including stroke, death, myocardial infarction, or TIA) during 30-day follow-up was
$4.5 \%$, while the composite complication rate comprising only stroke and death was $2.9 \%$ [18]. In another study in which the effectiveness of the Gore Flow Reversal System was assessed compared to distal protection systems, there were fewer lesions in the MRI DWI study, but also a reduction in the number of neurological incidents (comprising stroke, death, and myocardial infarction) in the arm using the proximal protection system [19].

Still, it should be emphasised that the aforementioned trials included both symptomatic and asymptomatic patients, and that the percentage of symptomatic patients in these studies was not higher than $40 \%$. By contrast, in our survey only symptomatic patients were included. Of note, there were 
no periprocedural neurological adverse events in our patients, while mid-term follow-up has revealed a complication rate of $0.8 \%$, which is much less in comparison with the other studies. In our opinion, such a low complication rate has resulted from the fact that in our centre the proximal protection was the preferred method for the management of symptomatic patients, even those presenting with critical stenosis or contralateral occlusion [20-22]. In contrast to the results of the meta-analysis performed by Bersin et al. [22], in our study adverse events were not more prevalent in patients older than 80 years, except for more frequent intolerance of the protection system.

However, a contralateral occlusion or significant stenosis represents an important limitation of the proximal protection technique. The maximal tolerated time of the occlusion of the ICA by a proximal protection device, according to different authors, should not exceed 2.5-15 $\min$ [21]. Of note, in our patient series $5(4.2 \%)$ individuals presented with an occlusion of contralateral internal carotid artery, while 25 (20.8\%) patients had severe bilateral stenosis of the ICAs. Neurological symptoms during introduction of the system occurred in 5 patients, including two individuals with bilateral stenosis. Nonetheless, there were no clinical consequences associated with such intolerance. Importantly, all of the aforementioned neurological symptoms occurred during procedures, which were longer than 6-7 min. This further confirms the validity of the 5-minute threshold as the safe time of endovascular carotid revascularisation [21].

The use of closed-cell stents could also account for the low stroke rate in our study. Superiority of the closed-cell stents in comparison with the opencell ones has already been demonstrated in several trials [23-25]. In 29 patients we implanted modern dual-layered stents (the RoadSaver stents). These stents are optimal in cases of severely narrowed artery and also in cases of distal (C2-C4 segments of the ICA) revascularisation. Good clinical results of carotid stenting with the use of such designed stents have already been reported [26-28]. Finally, an experience of the interventionalists should not be ignored [29]. There seems to be a learning curve with significant drop in the incidence of adverse events after more than 200 procedures performed $[29,30]$. Other studies have already reported the expertise of the operator as an independent factor associated with fewer complications. Besides, closed- cell stents, which are safer but also more difficult to implant, are more willingly used by experienced doctors [24].

We are aware of some limitations of this report. Firstly, our results are based on the retrospective assessment of data from our registry. Secondly, these results were not compared with surgical carotid endarterectomy or with endovascular treatments with the use of filters.

\section{Conclusions}

In our patient series the endovascular treatment of symptomatic carotid stenosis under proximal protection was safe and feasible. It appeared to be a good alternative to carotid endarterectomy. Low incidence of serious neurological adverse events was probably related to extensive operator experience, short time of carotid artery occlusion, and tailored use of the closed-cell or dual-layered stents.

\section{Conflict of interest}

The authors declare no conflict of interest.

\section{References}

1. Mas JL, Chatellier G, Beyssen B, et al. Endarterectomy versus stenting in patients with symptomatic severe carotid stenosis. N Engl J Med 2006; 355: 1660-71.

2. Wimmer NJ, Yeh RW, Cutlip DE, et al. Risk prediction for adverse events after carotid artery stenting in higher surgical risk patients. Stroke 2012; 43: 3218-24.

3. Bangalore S, Kumar S, Wetterslev J, et al. Carotid artery stenting vs carotid endarterectomy: meta-analysis and diversity-adjusted trial sequential analysis of randomized trials, Arch Neurol 2011; 68: 172-84.

4. Massop D, Dave R, Metzger C, et al. SAPPHIRE Worldwide Investigators, Stenting and angioplasty with protection in patients at high-risk for endarterectomy: SAPPHIRE Worldwide Registry first 2,001 patients. Catheter Cardiovasc Interv 2009; 73: 129-36.

5. Brott TG, Hobson RW, Howard G, et al. Stenting versus endarterectomy for treatment of carotid-artery stenosis. N Engl J Med 2010; 363: 11-23.

6. Ederle J, Dobson J, Featherstone RL, et al. Carotid artery stenting compared with endarterectomy in patients with symptomatic carotid stenosis (International Carotid Stenting Study): an interim analysis of a randomised controlled trial. Lancet 2010; 375: 985-97.

7. Eskandari MK, Najjar SF, Matsumura JS, et al. Technical limitations of carotid filter embolic protection devices. Ann Vasc Surg 2007; 21: 403-7.

8. Finol EA, Siewiork GM, Scotti CM, et al. Wall apposition assessment and performance comparison of distal protection filters. J Endovasc Ther 2008; 15: 177-85. 
9. Hobson RW $2^{\text {nd }}$, Howard VJ, Roubin GS, et al. Carotid artery stenting is associated with increased complications in octogenarians: 30-day stroke and death rates in the CREST lead-in phase. J Vasc Surg 2004; 40: 1106-11.

10. Cremonesi A, Gieowarsingh S, Spagnolo B, et al. Safety, efficacy and long-term durability of endovascular therapy for carotid artery disease: the tailored-Carotid Artery Stenting Experience of a single high-volume centre (tailored-CASE Registry). Eurointervention 2009; 5: 589-98.

11. Pieniazek P, Musialek P, Kablak-Ziembicka A, et al. Carotid artery stenting with patient- and lesion-tailored selection of the neuroprotection system and stent type: early and 5-year result from a prospective academic registry of 535 consecutive procedures (TARGET-CAS). J Endovasc Ther 2008; 15: 249-62.

12. Ansel GM, Hopkins LN, Jaff MR, et al. Safety and effectiveness of the INVATEC MO.MA proximal cerebral protection device during carotid artery stenting: results from the ARMOUR pivotal trial. Catheter Cardiovasc Interv 2010; 76: 1-8.

13. Pieniazek P, Tekieli L, Musialek P, et al. Carotid artery stenting according to the tailored-CAS algorithm is associated with a low complication rate at 30 days: data from the TARGET-CAS study. Kardiol Pol 2012; 70: 378-86.

14. Bijuklic K, Wandler A, Hazizi F, Schofer J. The PROFI study (Prevention of Cerebral Embolization by Proximal Balloon Occlusion Compared to Filter Protection During Carotid Artery Stenting): a prospective randomized trial. J Am Coll Cardiol 2012; 59: 1383-9.

15. Montorsi P, Caputi L, Galli S, et al. Microembolization during carotid artery stenting in patients with high-risk, lipid-rich plaque. A randomized trial of proximal versus distal cerebral protection. J Am Coll Cardiol 2011; 58: 1656-63.

16. Cano MN, Kambara AM, de Cano SJ, et al. Randomized comparison of distal and proximal cerebral protection during carotid, artery stenting. JACC Cardiovasc Interv 2013; 6: 1203-9.

17. Stabile E, Salemme L, Sorropago G, et al. Proximal endovascular occlusion for carotid artery stenting: results from a prospective registry of 1,300 patients. J Am Coll Cardiol 2010; 55: 1661-7.

18. Clair DG, Hopkins LN, Mehta M, et al. Neuroprotection during carotid artery stenting using the GORE flow reversal system: 30-day outcomes in the EMPiRE Clinical Study. Catheter Cardiovasc Interv 2011; 77: 420-9.

19. Kajihara Y, Sakamoto S, Kiura Y. Comparison of dual protection and distal filter protection as a distal embolic protection method during carotid artery stenting: a single-center carotid artery stenting experience. Neurosurg Rev 2015; 38: 671-6.

20. Hornung M, Bertog SC, Franke J, et al. Evaluation of proximal protection devices during carotid artery stenting as first choice for embolic protection. Eurolntervention 2015; 10: 1362-7.

21. Latacz P, Simka M, Popiela T, et al. Early results of endovascular treatment of patients with bilateral stenoses of the internal carotid arteries using proximal protection systems at 30-day follow-up. Neurol Neurochir Pol 2017; 51: 375-81.

22. Bersin RM, Stabile E, Ansel GM, et al. A meta-analysis of proximal occlusion device outcomes in carotid artery stenting. Catheter Cardiovasc Interv 2012; 80: 1072-8.

23. Bosiers M, de Donato G, Deloose K, et al. Does free cell area influence the outcome in carotid artery stenting? Eur J Vasc Endovasc Surg 2007; 33: 135-41.
24. Wodarg F, Turner E, Dobson J, et al. Influence of stent design and use of protection devices on outcome of carotid artery stenting - a pooled analysis of individual patient data. J Neurointerv Surg 2018; 10: 1149-54.

25. de Vries EE, Meershoek AJA, Vonken EJ, et al. A meta-analysis of the effect of stent design on clinical and radiologic outcomes of carotid artery stenting. J Vasc Surg 2019; 69: 1952-61.

26. Hopf-Jensen S, Marques L, Preiß M, et al. Initial clinical experience with the micromesh Roadsaver carotid artery stent for the treatment of patients with symptomatic carotid artery disease. J Endovasc Ther 2015; 22: 220-5.

27. Musialek P, Mazurek A, Trystula M, et al. Novel PARADIGM in carotid revascularisation: Prospective evaluation of All-comer peRcutaneous cArotiD revascularisation in symptomatic and Increased-risk asymptomatic carotid artery stenosis using

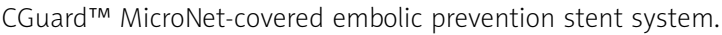
Eurolntervention 2016; 12: e658-70.

28. Stabile E, de Donato G, Musialek P, et al. Use of dual-layered stents in endovascular treatment of extracranial stenosis of the internal carotid artery: results of a patient-based meta-analysis of 4 clinical studies. JACC Cardiovasc Interv 2018; 11: 2405-11.

29. Ielasi A, Latib A, Godino C, et al. Clinical outcomes following protected carotid artery stenting in symptomatic and asymptomatic patients. J Endovasc Ther 2010; 17: 298-307.

30. Latacz P, Simka M, Brzegowy P, et al. Patient- and lesion-tailored algorithm of endovascular treatment for arterial occlusive disease of extracranial arteries supplying the brain: safety of the treatment at 30-day follow up. Adv Interv Cardiol 2017; 13: 53-61.

Submitted: 1.03.2020, accepted: 29.03.2020 